\title{
The human capsular bag model of posterior capsule opacification
}

\author{
I. Michael Wormstone ${ }^{1}$
}

Received: 8 October 2019 / Accepted: 24 October 2019 / Published online: 19 November 2019

(c) The Author(s), under exclusive licence to The Royal College of Ophthalmologists 2019

\begin{abstract}
Posterior capsule opacification (PCO) is the most common complication following cataract surgery and affects millions of patients. PCO is a consequence of surgical injury promoting a wound-healing response. Following surgery, residual lens epithelial cells grow on acellular regions of the lens capsule, including the central posterior capsule. These cells can undergo fibrotic changes, such that cell transdifferentiation to myofibroblasts, matrix deposition and matrix contraction can occur, which contribute to light scatter and the need for further corrective Nd:YAG laser capsulotomy in many patients. It is therefore of great importance to better understand how PCO develops and determine better approaches to manage the condition. To achieve this, experimental systems are required, and many are available to study PCO. While there may be a number of common features associated with PCO in different species, the mechanisms governing the condition can differ. Consequently, where possible, human systems should be employed. The human capsular bag model was established in a laboratory setting on donor eyes. A capsulorhexis is performed to create an opening in the anterior capsule followed by removal of the lens fibre mass. Residual fibre cells can be removed by irrigation/aspiration and if required, an intraocular lens can be implanted. The capsular bag is isolated from the eye and transferred to a dish for culture. The human capsular bag model has played an important role in understanding the biological processes driving PCO and enables evaluation of surgical approaches, IOLs and putative therapeutic agents to better manage PCO.
\end{abstract}

\section{Cataract surgery}

Cataract affects the vision and well-being of millions. At present, the only means of treating cataract is through surgical intervention [1]. Modern cataract surgery involves making a small incision in the sclera or cornea to allow the surgeon to introduce surgical tools to the eye. The iris is dilated to improve the operating view. A central piece of the anterior capsule is typically removed by capsulorhexis. This allows the surgeon access to the lens fibre mass, which is often the cataractous region. This material is removed by phacoemulsification and on rare occasions by hydroexpression. This procedure generates a capsular bag, which comprises a ring of anterior lens capsule and the entire posterior capsule. Best efforts are made to remove residual fibre material from the capsular bag and an intraocular lens (IOL) implant is placed within it. In essence this procedure

I. Michael Wormstone

i.m.wormstone@uea.ac.uk

1 School of Biological Sciences, University of East Anglia, Norwich, UK maintains separation of the aqueous and vitreous humours and through the introduction of the IOL restores visual power.

\section{Posterior capsule opacification}

Initial surgical outcomes from cataract surgery are excellent, but with time lens cells that remain following the operation undergo a wound-healing response [1-3]. In effect, the trauma of surgery provokes cells to proliferate and migrate across the acellular capsular surfaces and in some case the IOL surface. Most importantly, cells ultimately grow on to the previously cell-free central posterior capsule and undergo fibrotic events [2] that are associated with cell transdifferentiation to myofibroblasts, matrix deposition and matrix contraction that can lead to a secondary loss of vision termed posterior capsule opacification (PCO), which requires additional $\mathrm{Nd}$ :YAG laser capsulotomy if vision is sufficiently impaired [3]. PCO affects a large proportion of patients and is one of the most common fibrotic conditions in the world [2]. It is therefore of great importance to better understand this condition and thus powerful experimental systems are required for this purpose. 


\section{The human capsular bag model}

Many experimental systems are available to study PCO, with each presenting their own strengths and weaknesses [1]. A major point of consideration is species variation [4]. While there may be a number of common features associated with PCO in different species the mechanisms governing the condition can differ. Consequently, where possible, human systems should be employed as these provide the best opportunity to fully understand the biological basis of human PCO and provide more relevant evaluation tools for pharmacological agents and implanted devices. With this in mind, the human capsular bag model was developed [5-7] and has served as a valuable tool to understand the biological processes driving PCO [8-10] and to evaluate, surgical methods $[11,12]$, IOLs $[13,14]$ and putative therapeutic agents [15-19].

\section{Establishing the model}

A key factor in the development of the human capsular bag model was the availability of human donor eyes. This valuable resource provided by the generosity of individuals and loved ones has enabled significant advances to be made that have and will continue to provide benefit to patients. In general, greater efforts are being directed to the use of human donor material for eye research, but maintaining a good supply of tissue is a priority [20]. The human lens in particular has biological features that further increase its value as an experimental system and relevance to clinical settings [4]. The first capsular bag models were established in the mid-1990s using human tissue [5, 6]; however, the principle has been applied and adapted to other species [1].

The capsular bag model is prepared following key steps performed in standard cataract surgery. The cornea is generally absent from donor eyes and the iris can be removed, which allows a clear view of the lens. A capsulorhexis is performed to create an opening in the anterior capsule followed by removal of the lens fibre mass. This latter procedure is generally carried out by hydrodissection rather than phacoemulsification. Residual fibre cells can be removed by irrigation/aspiration. If required, an IOL can be implanted. The capsular bag is isolated from the eye and transferred to a dish for culture.

\section{Maintaining capsular bag shape}

Early models elected to isolate the capsular bag by cutting the zonules $[5,6]$. Using this approach it is possible to work with pure populations of lens cells associated with the capsular bag, which aids experimental design and interpretation. This approach is particularly useful for studies aiming to understand the cell biological and physiological processes involved with human PCO. However, isolating the bag removes the forces provided by the zonules to maintain its shape. If simply grown in tissue culture the dish without support, the preparation would shrivel and form a coiled ball of contorted capsule and cells, which would provide limited information to researchers. To maintain the shape of the isolated capsular bag, two general approaches were adopted. The first was to use a ring [6], implanted with the capsular bag, to maintain shape, but this approach was not commonly adopted. Another approach was to secure the capsular bag to a culture dish using entomological pins (Fig. 1) [5]. These pins penetrate the anterior and posterior capsules at the periphery of the bag and become embedded within the dish following a similar principle to a tent peg. Multiple pins (typically 8) are used to provide even support of the bag. This maintains the general shape of the bag, but also provides sufficient opportunity for cell-induced matrix modification to take place. Comments have been raised that the use of pins promotes injury, but this should be placed in context with the surgical procedure itself, which is far more severe and is the fundamental stimulus for wound-healing events observed in the bag. Nevertheless, penetrating the capsule does allow lens cells greater access to additional surfaces. The likelihood of cells advancing onto surfaces such as the peripheral outer anterior capsule and the culture dish are greatly influenced by the composition of the culture medium. Other approaches have aimed to establish a suspended capsular bag system, for example El-Osta et al. [21] initially secured the periphery of the capsular bag to a lens holder using medical-grade glue and introduced an IOL. This method was improved by Cleary et al. [7] through retention of the ciliary body and zonular fibres in association with the capsular bag. The ciliary body is pinned to a silicone ring leaving the capsular suspended in the lumen of the ring. Due to the presence of the ciliary body in this model, which introduces multiple cell types it is more complex to use this system to identify specific biological factors involved in specific events associated with PCO. It does however provide an excellent platform to assess general PCO progression and the influence of IOLs and pharmacological agents on PCO.

\section{Culture conditions}

As is common with in vitro cell and tissue culture, the standard culture conditions initially used was standard medium e.g. EMEM or DMEM supplemented with FCS/ FBS; this was usually at 5-10\% [5]. An antibiotic, usually gentamicin or penicillin/streptomycin, to ward off possible 


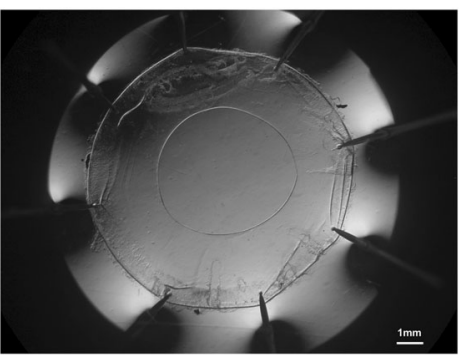

Fig. 1 Low-power, modified dark-field superior view of a human capsular bag preparation, secured to a culture dish using entomological pins and immersed in culture medium

infections is also added. The purpose of supplementing the medium with FCS is to maintain cell survival and promote growth. It is however, important to note that in its natural setting the lens does not have direct access to a blood supply and is bathed in relatively poor environmental conditions. The fact that the lens can stay transparent for decades of life is testament to its endogenous survival skills, such that it is known that the lens produces many of the proteins within the aqueous humour that will in turn support its maintenance [22]. With this in mind, Wormstone et al. [23] assessed the ability of cells within the human capsular bag to survive and grow in serum-free medium i.e. a simple culture medium (EMEM) with no added serum or protein supplements. Under these basal culture conditions, lens cells were found to not only survive, but grow across the posterior capsule. Strikingly, these cells were still actively synthesising proteins following more than a year in culture. This discovery greatly increased the value of the model. The use of high serum could be used to drive growth maximally if required. On the other hand, the ability to maintain cultures in serum-free medium provides a rare opportunity to assess the effects of a specific molecule or pathway through addition and inhibition studies, which allow assessment of cellular events within the capsular bag and analysis of the medium if desired.

A number of factors have been identified using the capsular bag model to have putative roles in PCO formation through a combination of autocrine and paracrine regulation. A number of investigations using the capsular bag model have identified molecules that could play a role in survival and growth, which are key physiological events following surgery that form the foundation for PCO. Candidates identified through this approach include fibroblast growth factor [9], hepatocyte growth factor [24], thrombin [25], epidermal growth factor [26] and vascular endothelial growth factor [8].

Fibrosis is a key aspect of PCO and features/markers for this have been identified in post-mortem capsular bag samples [2]. The most well-documented molecule associated with fibrosis throughout the body is transforming growth factor $\beta[27,28]$. It was therefore logical to study this molecule in the capsular bag model and see if TGF $\beta$ treatment in vitro could mimic changes observed in patients $[10,29,30]$. It was found that TGF $\beta$ was capable of promoting cell transdifferentiation to myofibroblasts, detected by alpha SMA expression, increased matrix production, enhanced matrix contraction and elevated levels of matrix metalloproteinases [10]. These changes mimicked findings from post-mortem capsular bag tissue [10]. It was discovered at a later date that a relatively short exposure of TGF $\beta$ was capable of inducing long-term effects i.e. maintain transdifferentiation and promote matrix contraction [30]. The knowledge that TGF $\beta$ can mimic clinical changes strongly implicate its involvement in human PCO. As a result, introduction of TGF $\beta$ to the model can be used to promote fibrosis and permits investigation of the fundamental pathways and mechanisms driving fibrosis and PCO in a human system.

Wherever possible it is good to use human products. The majority of the growth factors employed are human recombinant, but more recently efforts have been made to substitute FCS with human serum [14, 31]. This was initially maintained at a constant level throughout culture in order to drive growth in a similar manner to previous work employing FCS [13, 31]. However, changes to the ocular environment following cataract surgery are transient, peaking in the days week following surgery and return to a baseline state over time [32]. Eldred et al. [14] therefore set about making the maintenance conditions for capsular bag cultures better reflect the clinical scenario. To achieve this human serum was used to drive growth and TGF $\beta 2$ to promote fibrotic responses. Both human serum and TGF $\beta 2$ were added in a graded manner, such that cultures were exposed to maximum levels over the first 3 days of culture which was then reduced in a graded manner before continued maintenance of cultures for the remaining culture period in serum-free medium. As predicted growth and light scatter was accelerated (Fig. 2) and fibrotic responses were enhanced (Fig. 3) in graded culture.

\section{Assessing surgical techniques}

The human capsular bag model allows surgical methods to be compared in relation to cell behaviour and PCO progression. For example, Quinlan et al. [12] compared the impact of different methods to remove the fibre mass, namely hydroexpression and phacoemulsification. Matchpaired capsular bags were maintained in serum-free or serum-supplemented culture conditions following surgery. No difference in cell survival and growth was observed. Any benefits in patients from phacoemulsification relative to hydroexpression are likely to result from 
Fig. 2 Assessment of growth characteristics and matrix modification in capsular bags maintained under graded culture (Days $1-3,5 \%$ human serum and 10 ng/ml TGF $\beta 2$; Days 4-7, 2\% human serum and $1 \mathrm{ng} / \mathrm{ml}$ TGF $\beta 2$; Days 8-14, 1\% human serum and $0.1 \mathrm{ng} / \mathrm{ml} \mathrm{TGF} \beta 2$; Days 15-28 serum-free) or serum-free (SF) culture conditions. Progressive movement of cells (leading edge indicated by white arrows) was observed, initially on the peripheral posterior capsule (Day 7), then beyond the rhexis margin (black arrows) onto the central posterior capsule (days 14, 21 and 28). Note that wrinkling of the posterior capsule is associated with movement in graded cultures, whereas serum-free cultures exhibit matrix wrinkling once movement has been arrested [14]
A

Day 7
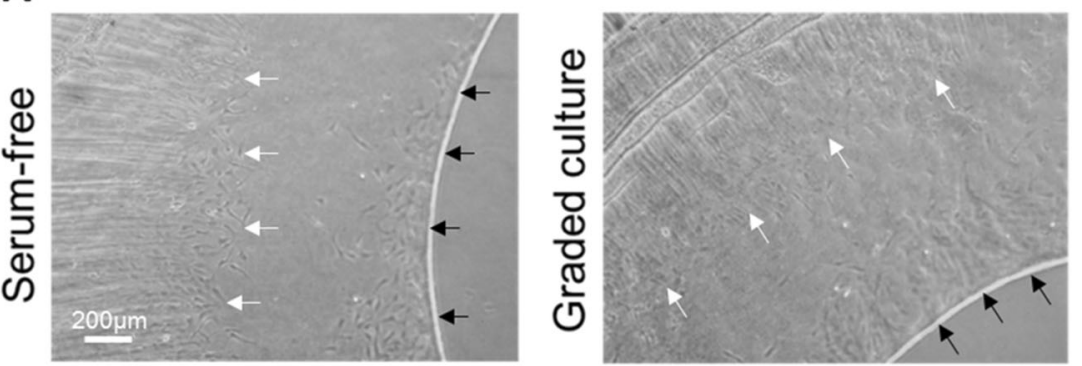

Day 14

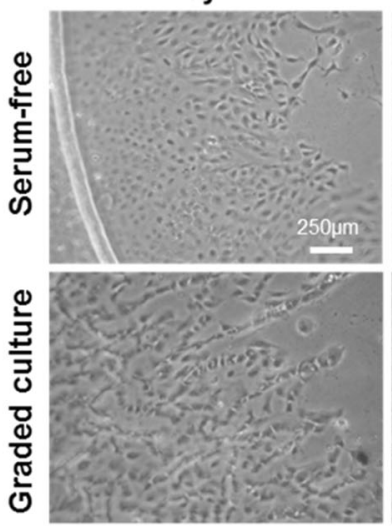

Day 21
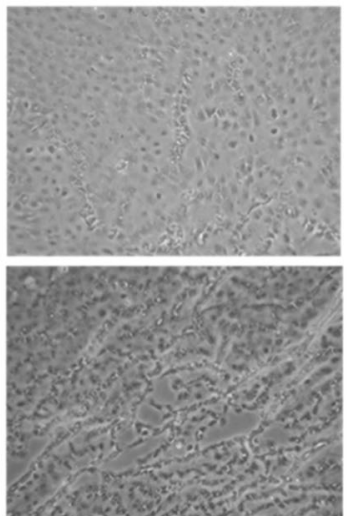

Day 28

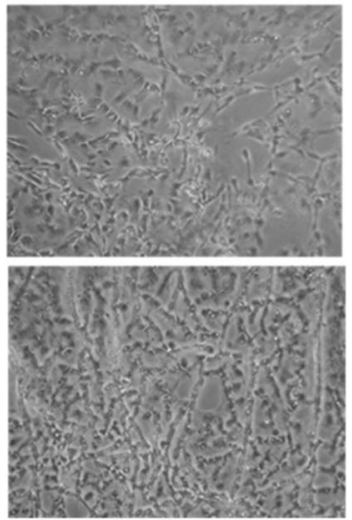

the smaller incision size and reduced inflammation due to this [33]. Therefore, in the laboratory setting either method is applicable and will ultimately perform the same role. The capsular bag model has also been used to assess if femtosecond laser capsulotomy could alter PCO formation relative to conventional manual capsuorhexis; in this study they concluded that no significant difference was observed [11].

\section{Evaluation and development of IOLS}

The most commonly used experimental system to evaluate IOLs is the in vivo rabbit model [34, 35]. This is largely due to the size of the rabbit lens being similar to a human lens and the argument that it offers an accelerated form of PCO. Human capsular bag models provide an alternative model for IOL research and development [5, 7, 13, 14, 17, 31, 36]. For example, the capsular bag model contributed greatly in the development of the Bag-in-the-lens IOL developed by Tassignon [36], which is now a commercially available IOL used successfully in clinical practice. The model has been developed and further improved over time in order to better enable IOL development. The original capsular bag model was first used to investigate the effect of IOLs [5]. This model secured the capsular bag (anterior surface up) to a dish using entomological pins at the equator, which resulted in a major point of contact with the capsule at the centre of
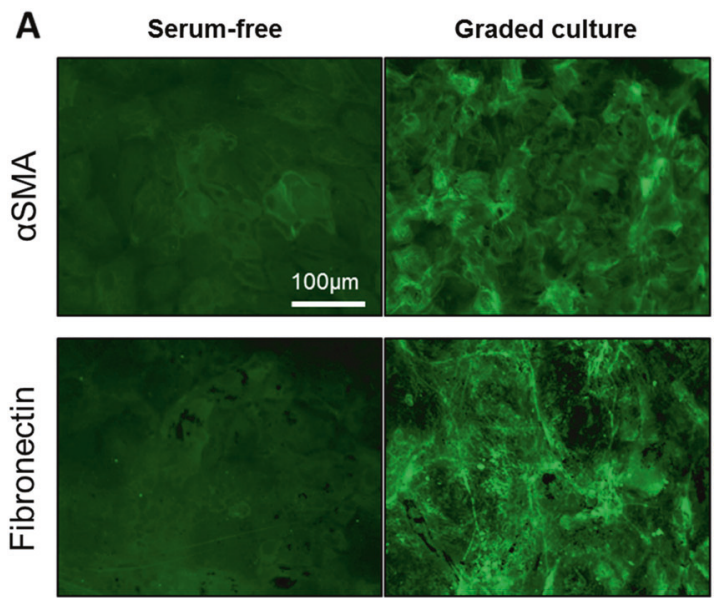

Fig. 3 Representative epifluorescence micrographs showing the distribution of the myofibroblast marker, $\alpha$-smooth muscle actin and the matrix component, fibronectin associated with cells growing on the central posterior capsule of human lens capsular bag preparations maintained in serum-free (SF) or graded culture conditions. Images were captured at end-point (Day 28) [14]

the optic and weak interaction at the optic edge. To improve the interaction between the capsule and optic, to better reflect the in vivo scenario, Dawes et al. [31] inverted the bag containing an IOL i.e. secured the bag containing the IOL anterior capsule down. This approach provided greater interaction between the optic edge and allowed the barrier effect seen with square edge IOLs to be studied. In addition, 
Dawes et al. [31] fully humanised this system using human serum and human recombinant TGF $\beta 2$ to drive growth and fibrosis. The introduction of suspended capsular bag models, however, has enhanced the utility of the bag model to study the effects of IOLs on PCO. As described earlier suspended capsular bag models maintain capsular bag integrity and allow the IOL to sit within it in a similar manner to in vivo [7, 14] (Fig. 4). The suspended model has been used to determine that IOL stability can be affected by an absence of lens cells [37]. Therefore, if efforts to ablate the residual cell population, by surgical or pharmacological means, are adopted in the future, modification of IOL design to improve stability in a cell-free bag is required. The suspended capsular bag model has also been used to test an open-bag IOL (Anew Zephyr) against the Alcon Acrysof [13]. The Alcon Acrysof is a traditional closed bag device that permits contact between the anterior and posterior capsules. The consequence of this is to "shrink wrap" the IOL, which is believed to provide a greater barrier at the edge of the IOL optic. This theoretically is believed to impede cell movement and ultimately PCO. It is known clinically that standard square-edge closed bag IOLs such as Alcon Acrysof slow, but do not prevent PCO. The Anew Zephyr IOL in contrast partitions the anterior and posterior capsules. The Anew Zephyr IOL outperformed the Alcon Acrysof in each match-paired experiment performed and suggest this fundamental design is worthy of development in the future [13]. These previous studies assessing IOLs in the bag had typically used constant serum levels or employed serum-free conditions. As this doesn't reflect the transient nature of proteins in the aqueous humour following cataract surgery, the graded culture model was employed to compare two common square-edge hydrophobic acrylic IOLs (Hoya Vivinex and Alcon Acrysof) under environmental conditions more reflective of the clinical scenario [14]. The graded culture regime provides a direct stimulus to residual lens cells following surgery. Using this approach, key observations of cell growth can be obtained on both the posterior capsule and IOL surface. In addition light scatter, myofibroblast expression and matrix deposition can be determined at end-point [14]. It should also be noted that many of the factors present in serum and supplemented TGF $\beta 2$ can bind to the lens capsule $[30,38]$. This essentially means that the capsule provides a reservoir of growth factors that can continue to regulate cells long after the external stimulus has been removed. Enrichment of the IOL by serum and added proteins is likely to be less long-lived than on the capsule. As culture progresses, growth on the IOL can recede to some degree, which links well with clinical observations [39]. At present, the graded culture in conjunction with a suspended capsular bag model appears to provide the best in vitro system to evaluate and develop IOLs [14].

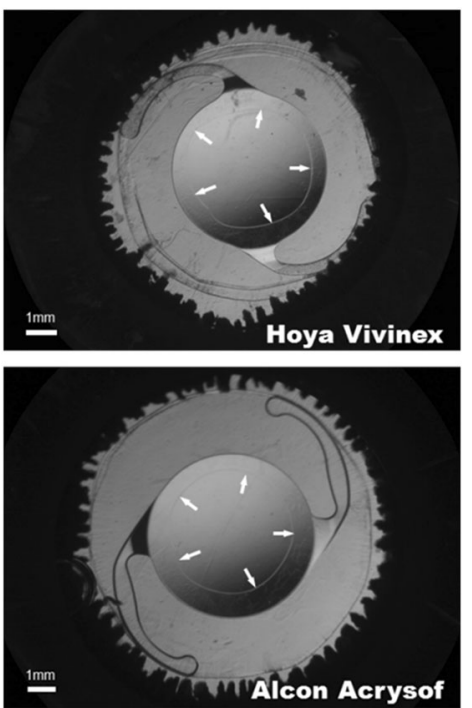

Fig. 4 Representative modified dark-field images of match-paired capsular bags implanted with a Hoya Vivinex or an Alcon Acrysof IOL captured on the day of simulated surgery. In both cases, the capsulorhexis (arrowed) is fully seated on the IOL optic [14]

\section{Putative therapeutic agents and drug delivery}

While improving IOL design to better manage PCO is logical, it is also likely that additional treatments using therapeutic agents or additional surgical approaches will be required to significantly reduce PCO formation and incidence. A recent paper has also indicated that this is a view held by a number of clinicians [40]. The capsular bag model has served as a valuable tool to test a number of therapeutic approaches. Therapeutic benefit could be derived from a number of strategies including complete ablation of cells within the bag $[16,17,41,42]$, prevention of matrix contraction/light scatter $[18,19,30]$ or inhibit growth/migration $[8,19,43,44]$. When the intention is to deliver a pharmacological agent it is important to consider how the agent can be delivered in a safe and effective manner. Again, the human capsular bag model has been used to assess drug delivery strategies. For example, the IOL itself can serve as a drug delivery device through surface coating and modification [15, 17, 44]. In addition, sealed drug delivery systems have also been used, which allow controlled drug exposure to lens cells within the capsular bag, but protects other ocular tissues $[16,45]$. In one study, double distilled water was delivered to the in vitro human capsular bag using the perfect capsule system with the intention of killing all cells at the time of surgery [16]. Interestingly, this approach was also performed in actual cataract surgery [45]. In both cases, the epithelium had a frosted appearance following surgery. This treatment did not successfully kill the entire lens epithelial cell population but did provide some 
slowing in the progression of PCO. This relative comparison of outcomes between the clinic and the human capsular bag model further highlights the value and predictive power this in vitro human model can provide.

\section{Summary}

The human capsular bag model provides an in vitro experimental system that reflects the clinical scenario following cataract surgery. The unique properties of the lens allow the culture environment to be controlled, which enables greater resolution of the factors regulating PCO progression. The human capsular bag model also permits evaluation of putative therapeutic agents with a stronger predictive power than is possible with animal models. In addition, the human capsular bag model can be used to assess and develop current and prototype IOL designs. The capsular bag model has therefore made a significant impact on PCO research and will continue to play a key role in developing strategies to better manage this common condition.

Acknowledgements The author would also like to thank all members of the eye research group past and present who have together with our colleagues at the Norfolk and Norwich University Hospital and around the world contributed to our evolving understanding of PCO. The efforts of the East Anglian Eye Bank, Filton Eye Bank and NHSBT are also greatly appreciated. Thanks also the generous funding bodies that have kindly supported work on the capsular bag model to date: The Humane Research Trust; British Council for the Prevention of Blindness; BBSRC; The John and Pamela Salter Trust; Cambridge Antibody Technology; Scientific Promotion of Ageing Research (SPARC); The Dunhill Medical Trust; The Lord Dowding Fund; The James Tudor Foundation; Fight for Sight; Anew Optics; Hoya Surgical Optics; Carl Zeiss Meditec AG; EPSRC.

\section{Compliance with ethical standards}

Conflict of interest The author declares that he has no conflict of interest.

Publisher's note Springer Nature remains neutral with regard to jurisdictional claims in published maps and institutional affiliations.

\section{References}

1. Wormstone IM, Eldred JA. Experimental models for posterior capsule opacification research. Exp Eye Res. 2016;142:2-12.

2. Eldred JA, Dawes LJ, Wormstone IM. The lens as a model for fibrotic disease. Philos Trans $\mathrm{R}$ Soc Lond B Biol Sci. 2011;366:1301-19.

3. Wormstone IM, Wang L, Liu CS. Posterior capsule opacification. Exp Eye Res. 2009;88:257-69.

4. Wormstone IM, Collison DJ, Hansom SP, Duncan G. A focus on the human lens in vitro. Environ Toxicol Pharm. 2006;21:215-21.
5. Liu CS, Wormstone IM, Duncan G, Marcantonio JM, Webb SF, Davies PD. A study of human lens cell growth in vitro. A model for posterior capsule opacification. Investig Ophthalmol Vis Sci. 1996;37:906-14.

6. Nagamoto T, Bissen-Miyajima H. A ring to support the capsular bag after continuous curvilinear capsulorhexis. J Cataract Refract Surg. 1994;20:417-20.

7. Cleary G, Spalton DJ, Zhang JJ, Marshall J. In vitro lens capsule model for investigation of posterior capsule opacification. J Cataract Refract Surg. 2010;36:1249-52.

8. Eldred JA, McDonald M, Wilkes HS, Spalton DJ, Wormstone IM. Growth factor restriction impedes progression of wound healing following cataract surgery: identification of VEGF as a putative therapeutic target. Sci Rep. 2016;6:24453.

9. Wormstone IM, Del Rio-Tsonis K, McMahon G, Tamiya S, Davies PD, Marcantonio JM, et al. FGF: An autocrine regulator of human lens cell growth independent of added stimuli. Investig Ophthalmol Vis Sci. 2001;42:1305-11.

10. Wormstone IM, Tamiya S, Anderson I, Duncan G. TGF-beta 2induced matrix modification and cell transdifferentiation in the human lens capsular bag. Investig Ophthalmol Vis Sci. 2002;43:2301-8.

11. Wertheimer C, Kreutzer TC, Dirisamer M, Eibl-Lindner K, Kook $\mathrm{D}$, Priglinger S, et al. Effect of femtosecond laser-assisted lens surgery on posterior capsule opacification in the human capsular bag in vitro. Acta Ophthalmologica. 2017;95:E85-E88.

12. Quinlan M, Wormstone IM, Duncan G, Davies PD. Phacoemulsification versus extracapsular cataract extraction: a comparative study of cell survival and growth on the human capsular bag in vitro. Br J Ophthalmol. 1997;81:907-10.

13. Eldred JA, Spalton DJ, Wormstone IM. An in vitro evaluation of the Anew Zephyr open-bag IOL in the prevention of posterior capsule opacification using a human capsular bag model. Investig Ophthalmol Vis Sci. 2014;55:7057-64.

14. Eldred JA, Zheng J, Chen S, Wormstone IM. An in vitro human lens capsular bag model adopting a graded culture regime to assess putative impact of IOLs on PCO formation. Investig Ophthalmol Vis Sci. 2019;60:113-22.

15. Wertheimer C, Kassumeh S, Piravej NP, Nilmayer O, Braun C, Priglinger $\mathrm{C}$, et al. The intraocular lens as a drug delivery device: in vitro screening of pharmacologic substances for the prophylaxis of posterior capsule opacification. Investig Ophthalmol Vis Sci. 2017;58:6408-18.

16. Duncan G, Wang L, Neilson GJ, Wormstone IM. Lens cell survival after exposure to stress in the closed capsular bag. Investig Ophthalmol Vis Sci. 2007;48:2701-7.

17. Duncan G, Wormstone IM, Liu CS, Marcantonio JM, Davies PD. Thapsigargin-coated intraocular lenses inhibit human lens cell growth. Nat Med. 1997;3:1026-8.

18. Eldred JA, Hodgkinson LM, Dawes LJ, Reddan JR, Edwards DR, Wormstone IM. MMP2 activity is critical for TGFbeta2-induced matrix contraction-implications for fibrosis. Investig Ophthalmol Vis Sci. 2012;53:4085-98.

19. Smith AJO, Eldred JA, Wormstone IM. Resveratrol inhibits wound healing and lens fibrosis: a putative candidate for posterior capsule opacification prevention. Investig Ophthalmol Vis Sci. 2019;60:3863-77.

20. Stamer WD, Williams AM, Pflugfelder S, Coupland SE. Accessibility to and quality of human eye tissue for research: a crosssectional survey of ARVO members. Investig Ophthalmol Vis Sci. 2018;59:4783-92.

21. El-Osta AA, Spalton DJ, Marshall J. In vitro model for the study of human posterior capsule opacification. J Cataract Refract Surg. 2003;29:1593-600. 
22. Davidson MG, Harned J, Grimes AM, Duncan G, Wormstone IM, McGahan MC. Transferrin in after-cataract and as a survival factor for lens epithelium. Exp Eye Res. 1998;66:207-15.

23. Wormstone IM, Liu CS, Rakic JM, Marcantonio JM, Vrensen GF, Duncan G. Human lens epithelial cell proliferation in a proteinfree medium. Investig Ophthalmol Vis Sci. 1997;38:396-404.

24. Wormstone IM, Tamiya S, Marcantonio JM, Reddan JR. Hepatocyte growth factor function and c-Met expression in human lens epithelial cells. Investig Ophthalmol Vis Sci. 2000;41:4216-22.

25. James C, Collison DJ, Duncan G. Characterization and functional activity of thrombin receptors in the human lens. Investig Ophthalmol Vis Sci. 2005;46:925-32.

26. Maidment JM, Duncan G, Tamiya S, Collison DJ, Wang L, Wormstone IM. Regional differences in tyrosine kinase receptor signaling components determine differential growth patterns in the human lens. Investig Ophthalmol Vis Sci. 2004;45:1427-35.

27. Leask A, Abraham DJ. TGF-beta signaling and the fibrotic response. FASEB J. 2004;18:816-27.

28. Derynck R, Budi EH. Specificity, versatility, and control of TGFbeta family signaling. Sci Signal. 2019;12:eaav5183.

29. Raghavan CT, Smuda M, Smith AJ, Howell S, Smith DG, Singh A, et al. AGEs in human lens capsule promote the TGFbeta2mediated EMT of lens epithelial cells: implications for ageassociated fibrosis. Aging Cell. 2016;15:465-76.

30. Wormstone IM, Anderson IK, Eldred JA, Dawes LJ, Duncan G. Short-term exposure to transforming growth factor beta induces long-term fibrotic responses. Exp Eye Res. 2006;83:1238-45.

31. Dawes LJ, Illingworth CD, Wormstone IM. A fully human in vitro capsular bag model to permit intraocular lens evaluation. Investig Ophthalmol Vis Sci. 2012;53:23-9.

32. Pande MV, Spalton DJ, Kerr-Muir MG, Marshall J. Postoperative inflammatory response to phacoemulsification and extracapsular cataract surgery: aqueous flare and cells. J Cataract Refract Surg. 1996;22:770-4.

33. Laurell CG, Zetterstrom C, Philipson B, Syren-Nordqvist S. Randomized study of the blood-aqueous barrier reaction after phacoemulsification and extracapsular cataract extraction. Acta Ophthalmol Scand. 1998;76:573-8.

34. Leishman L, Werner L, Bodnar Z, Ollerton A, Michelson J, Schmutz M, et al. Prevention of capsular bag opacification with a modified hydrophilic acrylic disk-shaped intraocular lens. J Cataract Refract Surg. 2012;38:1664-70.
35. Nishi O, Nishi K, Menapace R, Akura J. Capsular bending ring to prevent posterior capsule opacification: 2 year follow-up. J Cataract Refract Surg. 2001;27:1359-65.

36. De Groot V, Tassignon MJ, Vrensen GF. Effect of bag-in-the-lens implantation on posterior capsule opacification in human donor eyes and rabbit eyes. J Cataract Refract Surg. 2005;31:398-405.

37. Spalton DJ, Russell SL, Evans-Gowing R, Eldred JA, Wormstone IM. Effect of total lens epithelial cell destruction on intraocular lens fixation in the human capsular bag. J Cataract Refract Surg. 2014:40:306-12.

38. Tholozan FM, Gribbon C, Li Z, Goldberg MW, Prescott AR, McKie N, et al. FGF-2 release from the lens capsule by MMP-2 maintains lens epithelial cell viability. Mol Biol Cell. 2007;18: 4222-31.

39. Mullner-Eidenbock A, Amon M, Schauersberger J, Kruger A, Abela C, Petternel V, et al. Cellular reaction on the anterior surface of 4 types of intraocular lenses. J Cataract Refract Surg. 2001;27:734-40.

40. Shihan MH, Novo SG, Duncan MK. Cataract surgeon viewpoints on the need for novel preventative anti-inflammatory and antiposterior capsular opacification therapies. Curr Med Res Opin. 2019:35:1971-81.

41. Liu HR, Smith AJO, Ball SSR, Bao YP, Bowater RP, Wang NL, et al. Sulforaphane promotes ER stress, autophagy, and cell death: implications for cataract surgery. J Mol Med-Jmm. 2017;95:553-64.

42. Luft N, Kreutzer TC, Dirisamer M, Priglinger CS, Burger J, Findl $\mathrm{O}$, et al. Evaluation of laser capsule polishing for prevention of posterior capsule opacification in a human ex vivo model. J Cataract Refractive Surg. 2015;41:2739-45.

43. D'Antin JC, Barraquer RI, Tresserra F, Michael R. Prevention of posterior capsule opacification through intracapsular hydrogen peroxide or distilled water treatment in human donor tissue. Sci Rep. 2018;8:12739.

44. Wertheimer C, Siedlecki J, Kook D, Mayer WJ, Wolf A, Klingenstein A, et al. EGFR inhibitor Gefitinib attenuates posterior capsule opacification in vitro and in the ex vivo human capsular bag model. Graefes Arch Clin Exp Ophthalmol. 2015;253: 409-17.

45. Rabsilber TM, Limberger IJ, Reuland AJ, Holzer MP, Auffarth GU. Long-term results of sealed capsule irrigation using distilled water to prevent posterior capsule opacification: a prospective clinical randomised trial. Br J Ophthalmol. 2007;91:912-5. 